\title{
Patient controlled analgesia in children and adolescents: a randomized controlled trial
}

\author{
J.W.B. PETERS RN, MSN* ${ }^{*}$, I.E.N.G. BANDELL HOEKSTRA RN, \\ MSN + , H. HUIJER ABU-SAAD RN, PhDt, J. BOUWMEESTER MD*, \\ A.E.E. MEURSING MD, PhD*, D. TIBBOEL MD, PhD $\ddagger$ \\ * Sophia Children's Hospital, Department of Paediatric Anaesthesia, PO Box 2060, 3000 CB \\ Rotterdam, The Netherlands \\ † Maastricht University, Department of Nursing Science, PO Box 616, 6200 MD Maastricht, \\ The Netherlands \\ $\ddagger$ Sophia Children’s Hospital, Department of Paediatric Surgery, PO Box 2060, 3000 CB \\ Rotterdam, The Netherlands
}

\begin{abstract}
Summary
In children, patient controlled analgesia (PCA) and continuous infusion $(\mathrm{CI})$ of morphine are well established methods of relieving postoperative pain. This study was designed to assess the efficacy of PCA plus background infusion (BI) $\left(15 \mu \mathrm{g} \cdot \mathrm{kg}^{-1} \cdot \mathrm{h}^{-1}\right.$ and bolus doses of $15 \mu \mathrm{g} \cdot \mathrm{kg}^{-1}$ with a lock-out interval of $10 \mathrm{~min}$ ) with CI (20 to $\left.40 \mu \mathrm{g} \cdot \mathrm{kg}^{-1} \cdot \mathrm{h}^{-1}\right)$ in terms of analgesia, morphine needs and sideeffects. A stratified randomized controlled trial was carried out. 47 children aged 5-18 years undergoing major elective lower/upper abdominal or spinal surgery were allocated. The magnitude of surgery was assessed by the Severity of Surgical Stress scoring (SSS) system. Pain was assessed by self-report every three h. Side-effects compatible with morphine as well as morphine consumption were recorded. Morphine consumption was significantly increased in the PCA group compared with the CI group. Moreover, morphine consumption was associated with SSS, independent of the technique of administration. There were no significant differences between groups in pain scores or in the incidence of side-effects.
\end{abstract}

Keywords: analgesia: patient controlled; pain: postoperative; morphine: random clinical trial

\section{Introduction}

Patient controlled analgesia (PCA) without (PCA $-\mathrm{BI})$ or with a background infusion $(\mathrm{PCA}+\mathrm{BI})$ and continuous infusion $(\mathrm{CI})$ of morphine are well established methods of relieving postoperative pain

Correspondence to: Jeroen W.B. Peters, Sophia Children's Hospital, Department of Paediatric Anaesthesia, PO Box 2060, 3000 CB Rotterdam, The Netherlands. in children (1-3). PCA meets the prerequisites for effective analgesia, i.e. the opioid dosage is adjusted to the individual requirements and plasma concentrations are maintained at a constant level (4). Studies in children comparing PCA-BI with CI reported divergent results. In one study PCA decreased the morphine consumption and improved analgesia (5), while in another study PCA increased the morphine needs and improved analgesia in children aged 9-15 years $(6,7)$. In children, PCA + BI 
results in lower pain scores (3) and provides better sleep patterns (8) compared with PCA - BI. However, there are no studies which compare PCA + BI with $\mathrm{CI}$ in children. We hypothesized that children treated with PCA + BI will have a decrease in pain score of $15 \mathrm{~mm}$ assessed on a validated pain score system: i.e. the visual analogue scale (VAS; 0-100 mm), compared with children who receive $\mathrm{CI}$ for postoperative pain relief. Additionally, morphine intake of children receiving PCA + BI will not be more than $25 \%$ higher than the morphine consumption of children receiving CI. To investigate this, a randomized controlled clinical trial was performed.

\section{Methods and measurements}

The study population consisted of 47 children, aged 5-18 years old, physical status ASA 1 or 2 and hospitalized for elective lower/upper abdominal or spinal surgery. Postoperatively the patients remained in a normal or medium care environment. Developmentally retarded children, those in whom caudal or regional blockade was used; and those who could not feel pain in the operated area (e.g. meningomyelocele) were excluded. The study was approved by the Medical Ethical Committee of the University hospital Rotterdam and written parental informed consent was obtained before the patients were entered into the study.

The day before surgery, children were instructed by one of the first two investigators how to use the measurement instruments and the PCA device.

Preoperatively only midazolam p.r.n. was administered. A standard anaesthetic technique was used; fentanyl was the only analgesic administered. At the end of the operation children were randomly assigned to either PCA + BI or CI. Randomization was based on a prestratification into three age groups (5-6, 7-11, 12-18 years), based on Piaget's stages of cognitive development (9). To guarantee equal group sizes, random permuted blocks (10) were used, using blocks of four patients' assignment.

Morphine was administered i.v. after surgery until the patients were pain free, at which time PCA or CI was started. The PCA pump (Graseby $3000^{\circledR}$, Watford, UK) was adjusted for bolus doses of $15 \mu \mathrm{g} \cdot \mathrm{kg}^{-1}$, a lockout interval of ten min and with a BI of $15 \mu \mathrm{g} \cdot \mathrm{kg}^{-1} \cdot \mathrm{h}^{-1}$. A BI of $15 \mu \mathrm{g} \cdot \mathrm{kg}^{-1} \cdot \mathrm{h}^{-1}$ was chosen because it represents $50 \%$ of average hourly requirements of children receiving PCA for postoperative pain $(3,8)$. The CI device (Braun perfusor $^{\circledR}$, Melsungen, Germany) was set between $20-40 \mu \mathrm{g} \cdot \mathrm{kg}^{-1} \cdot \mathrm{h}^{-1}$ which is proven to be efficacious in children (2).

The magnitude of the surgical stress was assessed in all children by an anaesthesiologist using the Severity of Surgical Stress coding system (SSS), consisting of seven factors that contribute to the stress of surgical trauma (11): i.e. the amount of blood loss, superficial dissection, visceral trauma, the site plus duration of surgery, associated stress factors and cardiac surgery. In this study, SSS scores will be relatively low, since cardiac surgery was not included.

Pain was rated by the children (except when asleep) using a $100 \mathrm{~mm}$ visual analogue scale (VAS). This scale has proven to be adequately understood by five-year-old children, and has satisfactory supportive data on validity (12). The pain measurements were made hourly for the first four $\mathrm{h}$ and thereafter once every three $h$. Morphine intake of the PCA group was registered by the PCA pump, and for the $\mathrm{CI}$ group by the nurses' registration on medication charts. Side-effects such as nausea, vomiting, urinary retention requiring bladder catheterization, slow and/or superficial breathing and itching were assessed and registered by the nurse, every three hours.

A consultant paediatric anaesthetist visited the patients every morning to check whether the technique was working satisfactorily and to readjust the BI or CI amounts according to the child's pain reports and general condition. PCA bolus dose amounts and the lock-out interval were not changed during the study.

The Mann Whitney $U$-test was used to analyse the demographic data and SSS scores between both groups. The serial measurement data, i.e. pain scores and morphine intake, were analysed using the summary measurement approach (13) and stepwise multiple linear regression analysis. For the purpose of the analyses, intervention was coded as 1 for $\mathrm{PCA}+\mathrm{BI}$ and 2 for CI. Data analysis was conducted according to 'intention to treat' principle.

Power analysis was based on the comparison of two independent means (14). An average difference of $15 \mathrm{~mm}$ was defined as clinically relevant. It was expected that $95 \%$ of the mean reported pain scores would range between 0 and $80 \mathrm{~mm}$, resulting in a 
Table 1

Demographic data

\begin{tabular}{|c|c|c|c|c|c|c|c|c|c|c|c|c|}
\hline & \multicolumn{2}{|c|}{ 5-6 years } & \multicolumn{2}{|c|}{$7-11$ years } & \multicolumn{2}{|c|}{$12-18$ years } & \multicolumn{2}{|c|}{ Nationality } & \multirow{2}{*}{$\begin{array}{l}\text { Age (yrs) } \\
\text { Median } \\
\text { (range) }\end{array}$} & \multirow{2}{*}{$\begin{array}{l}\text { Weight } \\
\quad(\mathrm{kg}) \\
\text { Median } \\
\text { (range) }\end{array}$} & \multirow{2}{*}{$\begin{array}{l}\text { Loading } \\
\text { dose } \\
\left(\mu g \cdot \mathrm{kg}^{-1}\right) \\
\text { Mean } \\
\text { (sd) }\end{array}$} & \multirow{2}{*}{$\begin{array}{c}\text { SSS } \\
\text { Median } \\
\text { (range) }\end{array}$} \\
\hline & M & $\mathrm{F}$ & $\mathrm{M}$ & F & M & $\mathrm{F}$ & Dutch & Other & & & & \\
\hline $\begin{array}{l}\text { PCA group } \\
(n=24)\end{array}$ & 2 & 4 & 7 & 6 & 3 & 2 & 18 & 6 & $\begin{array}{c}8.5 \\
(5-16)\end{array}$ & $\begin{array}{c}34 \\
(18-71)\end{array}$ & $\begin{array}{l}117 \\
(70)\end{array}$ & $\begin{array}{c}8.5 \\
(5-14)\end{array}$ \\
\hline $\begin{array}{l}\text { CI group } \\
(n=23)\end{array}$ & 3 & 0 & 7 & 7 & 1 & 5 & 19 & 4 & $\begin{array}{c}9.0 \\
(5-18)\end{array}$ & $\begin{array}{c}31 \\
(17-71)\end{array}$ & $\begin{array}{l}110 \\
(72)\end{array}$ & $\begin{array}{c}8 \\
(6-16)\end{array}$ \\
\hline Total & 5 & 4 & 14 & 13 & 4 & 7 & 37 & 10 & & & & \\
\hline$P$-value & & & & & & & & & n.s. & n.s. & n.s. & n.s. \\
\hline
\end{tabular}

M: male; F: female; n.s.; not significant.

standard deviation of $20 \mathrm{~mm}$. One sided testing with an alpha of 0.05 and a beta of 0.20 yielded a sample size of 44 patients. To correct for drop-outs it was decided to include 23 patients in each group.

\section{Results}

Demographic data on patients are presented in Table 1. Forty-seven children were included, 24 of them received $\mathrm{PCA}+\mathrm{BI}$ and $23 \mathrm{CI}$, most of these children $(57 \%)$ were between 7 and 11 years of age. There were no significant differences between the groups for age, weight, gender or nationality. Surgery was performed for a wide variety of indications, i.e. thoracotomy $(n=4)$, laparotomy upper abdomen $(n=$ $14)$, laparotomy lower abdomen $(n=11)$, lumbotomy $(n=9)$, thoracic wall correction $(n=5)$ and laminectomy $(n=2)$ (Table 2$)$. Type of surgery was equally divided between both groups and no significant differences (median (range)) in SSS or 'loading dose' morphine amounts were found between the CI and PCA group.

Missing values. Missing values were mainly due to children being asleep ( $9 \%$ in total), i.e. 27 times in the PCA and 25 times in the CI group. Other reasons reported by the nurses were: refusal $(1 \%)$, i.e. PCA twice and CI five times, and too sedated (1\%), i.e. PCA: six times and CI twice. Moreover, in 3\% of the measurement periods no reason was given for not assessing the pain, i.e. PCA ten times and CI seven times. No statistical differences were found between groups in the incidence of refusal, sedation or sleeping.
Pain. The mean pain scores for each child each day (Figure 1) were categorized as mild $(<30 \mathrm{~mm})$, moderate (30-60 mm) and severe $(\geq 60 \mathrm{~mm})(3)$. On the day of surgery, some children suffered severe pain in both the PCA and CI group; 19\% and 38\%, respectively. Moreover, neither of the techniques provided satisfactory analgesia (i.e. mild pain) at days 1 and 2 in about $50 \%$ of the children. To evaluate the overall efficacy of the PCA and CI techniques, stepwise multiple regression analysis was carried out with the variables: intervention, morphine consumption, SSS and age entered as the predictor variables, and postoperative pain as the outcome variable. None of these variables were statistically significant predictors of reported pain intensity.

Morphine intake. The mean morphine consumption for each day in both study groups is presented in Figure 2, showing that the PCA group consumed more morphine each day than the CI group. The overall difference was assessed using multiple regression analysis. A log transformation was carried out on the morphine consumption data, to confirm the assumption of normality. Stepwise multiple regression analysis was carried out with the predictor variables, intervention, SSS, age and pain. The latter two variables were not entered in the regression analysis due to partial $F$-values of 0.76 and 0.09 , respectively. Hence, the regression model contained only the variables intervention SSS and explained $62 \%$ of the variance, with an F-value of $34.81(P=0.0000)$ and a regression model of: $\log$ $\left(\right.$ morphine intake $\left.\left(\mu \mathrm{g} \cdot \mathrm{kg}^{-1} \cdot \mathrm{h}^{-1}\right)\right)=3.37+-0.45$ (intervention) +0.53 (SSS). The 95\% CI ( $P$-value) for the 
Table 2

Distribution of type of surgery in the study population.

\begin{tabular}{|c|c|c|}
\hline Type of surgery & $P C A$ & $C I$ \\
\hline \multicolumn{3}{|l|}{ Major postoperative pain } \\
\hline Thoracotomy & Lobectomy (2) & Lobectomy (2) \\
\hline Laparotomy upper abdomen & Splenectomy (2), adrenalectomy (1), & Splenectomy (1), liver-cyst (1), adrenalectomy (1) \\
\hline Laparotomy abdomen & $\begin{array}{l}\text { Gall bladder-surgery (1), bladder surgery (1), } \\
\text { intestinal resection ( } 2 \text { ) }\end{array}$ & \\
\hline Other & & nephrectomy (1) \\
\hline \multicolumn{3}{|l|}{ Moderate postoperative pain } \\
\hline Laparotomy lower abdomen & $\begin{array}{l}\text { Ureteral reimplantation (6), uterus amputation } \\
\text { (1) }\end{array}$ & Ureteral reimplantation (4) \\
\hline Lumbotomy & Pyeloplasty (1), partial nephrectomy (2), & $\begin{array}{l}\text { Pyeloplasty (3), partial nephrectomy (2), } \\
\text { elevation urethrostomy (1), } \\
\text { pectus excavatum correction (2) }\end{array}$ \\
\hline Sternum correction & Pectus excavatum correction (3) & \\
\hline Other & Open lung biopsy (1) & \\
\hline \multicolumn{3}{|l|}{ Minor postoperative pain } \\
\hline Laminectomy & Excision liquor cyst (1) & Excision bone tumour (1) \\
\hline
\end{tabular}

Numbers in parenthesis are numbers of children.

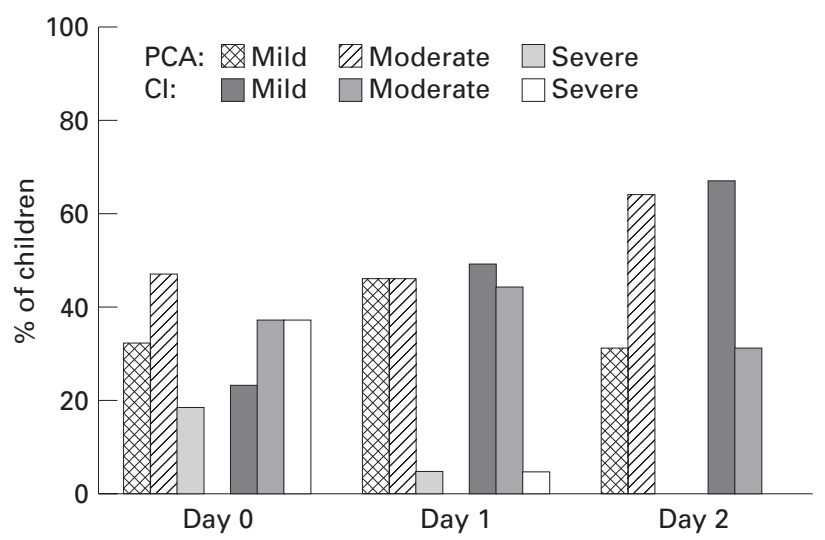

Figure 1

Distribution of daily mean individual pain scores.

predictors ranged between $\mathrm{e}^{-0.57}-\mathrm{e}^{-0.32} \quad(P=0.000)$ and $\mathrm{e}^{+0.03}-\mathrm{e}^{0.07}(P=0.000)$, respectively. Thus, when controlling for SSS, morphine consumption of children with $\mathrm{PCA}+\mathrm{BI}$ is about $57 \%$ greater than with CI. Moreover, morphine intake increases exponentially with increasing SSS, independent of the technique of morphine administration. No interaction was found between the independent variables. One patient, a girl of 5 years, receiving PCA, with an SSS of 6 and a morphine intake of $10.77 \mu \mathrm{g} \cdot \mathrm{kg}^{-1} \cdot \mathrm{h}^{-1}$, was

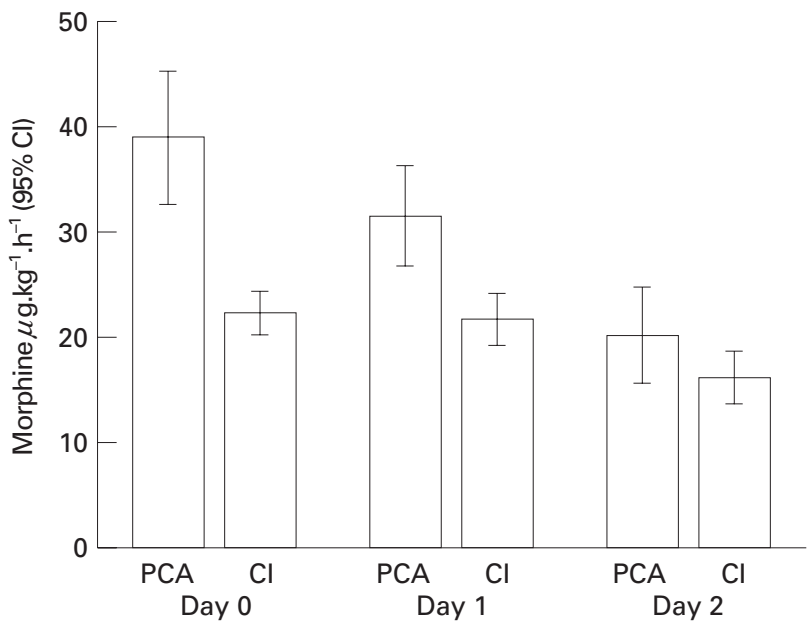

Figure 2

Distribution of cumulative daily morphine requirements (95\% confidence interval).

omitted from statistical analysis, due to a standard residual of $>-3.0$. In this case the $\mathrm{BI}$ infusion was stopped already at day one, while PCA was stopped at day two; this trend was uncommon compared with all other cases.

Side-effects. Nausea and vomiting were registered at least once in $11(46 \%)$ and $8(33 \%)$ patients of the PCA group, respectively; and in $7(30 \%)$ and $4(17 \%)$ 
children of the CI group, respectively. Itching was observed in two (8\%) patients of the PCA group, but not in the CI group. Urinary retention was found in both groups once $(4 \%)$, while superficial breathing was registered in one (4\%) patient of the PCA group. There was no statistical significance between the two groups for any of these side effects.

\section{Discussion}

PCA + BI $\quad\left(15 \mu \mathrm{g} \cdot \mathrm{kg}^{-1} \cdot \mathrm{h}^{-1}\right.$ with bolus doses of $\left.15 \mu \mathrm{g} \cdot \mathrm{kg}^{-1}\right)$ significantly increases morphine consumption, but does not increase analgesia or side-effects, compared with CI $\left(20-40 \mu \mathrm{g} \cdot \mathrm{kg}^{-1} \cdot \mathrm{h}^{-1}\right)$. Morphine consumption appears to depend on the severity of surgical stress. Missing values are unavoidable when using self-report measures $(1,15)$, and were mainly due to children being asleep or refusing to cooperate. In contrast to others (15), we have some reservations about assuming that children are not in pain when they sleep, because sleeping may be a coping strategy or the result of exhaustion. In the present study, no attempt was made to recode the missing values by use of physiological or observational measurement (instruments), since physiological changes are not specifically related to the severity of pain (16), while observational measures do not correlate with self-reports of postoperative pain in children (17). The summary measurement approach was used to cope with this problem (13).

The incidence of moderate to severe pain was high in both groups. The reason for this could be because multimodel analgesia (e.g. addition of acetaminophen or NSAIDs) was not used. Moreover, the paediatric anaesthetist might underestimate the severity of the postoperative pain as shown by the findings in the CI group (Figure 2), i.e. although morphine doses up to $40 \mu \mathrm{g} \cdot \mathrm{kg}^{-1} \cdot \mathrm{h}^{-1}$ could be administered, only two children received $>30 \mu \mathrm{g} \cdot \mathrm{kg}^{-1} \cdot \mathrm{h}^{-1}$. Findings in the PCA group suggest that the majority of children did not use the device to diminish their pain, even when they were instructed to self-administer more doses of morphine. Similar observations have been reported in children $>5$ years $(3,7,18)$ and in adults $(19,20)$. It is not clear why children and adults do not self-administer morphine at the point of mild pain. Patients may accept moderate pain which we, on the contrary, assume is associated with inadequate analgesia.

In this study, no differences in pain scores were found between the groups, although higher morphine amounts were used in the PCA group. We hypothesize that this might be related to the fact that PCA treated children used the PCA device to reduce pain caused by activity (21). In this study, however, pain assessment was not carried out during activity. Hence, further studies should incorporate these measures in rest as well as during activity. Additionally, psychological factors may also be held responsible. Among these factors, anxiety, neuroticism, depression, the family environment as well as the patient's type of locus of control have been shown to be related to the efficacy of postoperative pain treatment in adolescents and adults (22-27).

The use of a BI of $15 \mu \mathrm{g} \cdot \mathrm{kg}^{-1} \cdot \mathrm{h}^{-1}$ seems to be controversial. Other reports in children $>6$ years $(28$, 29 ) and adults (30) indicate that a concurrent BI does not reduce the frequency of self-administration of morphine or postoperative pain. In a series of studies in children undergoing appendicectomy $(21,28,29)$ it was concluded that a BI of $4 \mu \mathrm{g} \cdot \mathrm{kg}^{-1} \cdot \mathrm{h}^{-1}$ with bolus doses of $20 \mu \mathrm{g} \cdot \mathrm{kg}^{-1}$, and a lockout interval of five $\mathrm{min}$ is the most efficacious adjustment for PCA, since PCA-BI was associated with inadequate sleeping pattern, higher BI amounts increased side-effects while bolus doses of $10 \mu \mathrm{g} \cdot \mathrm{kg}^{-1}$ resulted in higher pain scores during activity. Other authors $(3,8)$, on the contrary, did not obtain any significant differences in morphine intake or side-effects, when comparing PCA-BI with PCA+BI. In these latter studies, however, bolus doses were smaller in those receiving PCA + BI. In the present study, the BI of $15 \mu \mathrm{g} \cdot \mathrm{kg}^{-1} \cdot \mathrm{h}^{-1}$ did not increase the incidence of sideeffects, compared with CI. Whether a lower BI would decrease the incidence of side-effects, without decreasing analgesia, is not clear and needs to be further investigated.

Another significant finding in our study relates to the association between SSS and morphine intake. The SSS scoring method, however, was developed by Anand and Aynsley-Green for neonates (11). These authors found that SSS scores discriminated between minor, moderate, and severe hormonal stress responses (e.g. plasma adrenaline, noradrenaline). Additionally, increasing SSS scores are associated 
with greater and more prolonged changes in hormonal plasma concentrations during and after surgery (11). In neonates, peroperative administration of opioids decreases the magnitude of stress hormone secretion and improves postoperative morbidity and mortality outcome $(31,32)$. In adult patients, similar hormonal stress responses and outcome values have been obtained $(33,34)$. For example, laparoscopic cholecystectomy triggers a minor hormonal stress response compared with conventional cholecystectomy. Moreover, in adults it was found that the magnitude of the stress reponse was associated with postoperative morphine requirements (33). Hence, the neonatal stress response to surgery is the same as in adults. It, therefore, seems valid to adapt the SSS scoring system for children and adolescents. In our study stress plasma levels were not determined, therefore care should be taken in interpreting the SSS-scores and increasing morphine requirements.

In children, $\mathrm{PCA}+\mathrm{BI}\left(15 \mu \mathrm{g} \cdot \mathrm{kg}^{-1}\right.$ bolus dose + $15 \mu \mathrm{g} \cdot \mathrm{kg}^{-1} \cdot \mathrm{h}^{-1} \quad$ BI) and CI of $20-40 \mu \mathrm{g} \cdot \mathrm{kg}^{-1} \cdot \mathrm{h}^{-1}$ provide similar but moderate postoperative analgesia. More studies are necessary to clarify why children do not use the PCA device to relieve mild pain. Psychological characteristics may contribute to this aspect and should be taken into account.

\section{References}

1 Bray RJ. Postoperative analgesia provided by morphine infusion in children. Anaesthesia 1983; 38: 1075-1078.

2 Hendrickson M, Myre L, Johnson DG et al. Postoperative analgesia in children: a prospective study in intermittent intramuscular injection versus continuous intravenous infusion of morphine. J Pediat Surg 1990; 25: 185-190.

3 Berde CB, Lehn BM, Yee JD et al. Patient-controlled analgesia in children and adolescents: a randomized, prospective comparison with intramuscular administration of morphine for postoperative analgesia. J Pediat 1991; 118: 460-466.

4 Ferrante FM, Orav EJ, Rocco AG et al. A statistical model for pain in patient controlled analgesia and conventional intramuscular opioid regimens. Anesth Analg 1988; 67: 457-461.

5 Mackie AM, Coda BC, Hill HF. Adolescents use patientcontrolled analgesia effectively for relief from prolonged oropharyngeal mucositis pain. Pain 1991; 46: 265-269.

6 Bray RJ, Woodhams AM, Vallis CJ et al. Morphine consumption and respiratory depression in children receiving postoperative analgesia from continuous morphine infusion or patient controlled analgesia. Paed Anaesth 1996; 6: 129-134.

7 Bray RJ, Woodhams AM, Vallis CJ et al. A double-blind comparison of morphine infusion and patient controlled analgesia in children. Paed Anaesth 1996; 6: 121-127.
8 Skues MA, Watson DM, O'Meara M et al. Patient-controlled analgesia in children. A comparison of two infusion techniques. Paed Anaesth 1993; 3: 223-228.

9 Piaget J, Inhelden B. The psychology of the child. New York: Basic Books, 1969.

10 Pocock SJ. Clinical trials: a practical approach. Chichester: John Waley \& Soas, 1987.

11 Anand KJ, Aynsley-Green A. Measuring the severity of surgical stress in newborn infants. J Pediat Surg 1988; 23: 297-305.

12 Abu-Saad HH, Pool H, Tulkens B. Further validity testing of the Abu-Saad Paediatric Pain Assessment Tool. J Adv Nurs 1994; 19: 1063-1071.

13 Matthews JNS, Altman DG, Campbell MJ et al. Analysis of serial measurements in medical research. Br Med J 1990; 300 230-235.

14 Kirkwood BR. Essentials of medical statistics. Oxford: Blackwell Science Ltd, 1988.

15 Walson PD, Graves PS, Mortensen ME et al. Patient-controlled versus conventional analgesia for postsurgical pain relief in adolescents. Dev Pharmacol Ther 1992; 19: 32-39.

16 McGrath PA. An assessment of children's pain: a review of behavioral, physiological and direct scaling techniques. Pain 1987; 31: 147-176.

17 Beyer FE, McGrath PJ, Berde CB. Discordance between selfreport and behavioral pain measures in children aged 3-7 years after surgery. I Pain Symptom Manag 1990; 5: 350-356.

18 Gaukroger PB, Tomkins DP, van der Walt JH. Patient-controlled analgesia in children. Anaesth Intensive Care 1989; 17: 264-268.

19 Owen H, Plummer JL, Armstrong I et al. Variables of patientcontrolled analgesia. 1. Bolus size. Anaesthesia 1989; 44: 7-10.

20 Owen H, Kluger MT, Plummer JL. Variables of patientcontrolled analgesia 4: the relevance of bolus dose size to supplement a background infusion. Anaesthesia 1990; 45: 619-622.

21 Doyle E, Mottart KJ, Marshall C et al. Comparison of different bolus doses of morphine for patient-controlled analgesia in children. Br J Anaesth 1994; 72: 160-163.

22 Taenzer P, Melzack R, Jeans ME. Influence of psychological factors on postoperative pain, mood and analgesic requirements. Pain 1986; 24: 331-342.

23 Lim AT, Edis G, Kranz $\mathrm{H}$ et al. Postoperative pain control: contribution of psychological factors and transcutaneous electrical stimulation. Pain 1983; 17: 169-188.

24 Feinmann C, Ong M, Harvey W et al. Psychological factors influencing post-operative pain and analgesic consumption. $\mathrm{Br}$ J Oral Maxillofac Surg 1987; 25: 285-292.

25 Ferrante FM. Patient characteristics influencing effective use of patient controlled analgesia. In: Ferrante FM, Ostheimer GW, Covino BG, eds. Patient controlled analgesia. Boston: Blackwell Scientific Publications, 1990: 51-60.

26 Gil KM, Ginsberg B, Muir M et al. Patient controlled analgesia: the relation of psychological factors to pain and analgesic use in adolescents with postoperative pain. Clin J Pain 1992; 8: 215-221.

27 Johnson LR, Magnani B, Chan V et al. Modifiers of patientcontrolled analgesia efficacy. I. Locus of control. Pain 1989; 39: $17-22$.

28 Doyle E, Harper I, Morton NS. Patient-controlled analgesia with low dose background infusions after lower abdominal surgery in children. Br J Anaesth 1993; 71: 818-822.

29 Doyle E, Robinson D, Morton NS. Comparison of patientcontrolled analgesia with and without a background infusion after lower abdominal surgery in children. Br J Anaesth 1993; 71: $670-673$ 
30 Owen H, Szekely SM, Plummer JL et al. Variables of patientcontrolled analgesia. 2. Concurrent infusion. Anaesthesia 1989; 44: 11-13.

31 Anand KJ, Sippell WG, Aynsley-Green A. Randomised trial of fentanyl anaesthesia in preterm babies undergoing surgery: effects on the stress response. Lancet 1987; 1: 62-66.

32 Anand KJ, Hickey PR. Halothane-morphine compared with high-dose sufentanil for anesthesia and postoperative analgesia in neonatal cardiac surgery. $N$ Engl J Med 1992; 326: 1-9.
33 Glaser F, Sannwald GA, Buhr HJ et al. General stress response to conventional and laparoscopic cholecystectomy. Ann Surg 1995; 221: 372-380.

34 Chernow B, Alexander HR, Smallridge RC et al. Hormonal responses to graded surgical stress. Arch Intern Med 1987; 147: 1273-1278.

Accepted 6 August 1998 